\title{
Psychiatric presentations to an A\&E department
}

\author{
David Ellis and Simon Lewis
}

\begin{abstract}
A survey is described of people presenting with poychiatric problems to a north London accident and emergency (A\&E) department over three months. Forty per cent presented with dellberate self-harm and $25 \%$ of these left before being aseessed. Twenty per cent of those with problems compatible with a diagnosis of severe mental illness also leff before being seen by a doctor. Differences between presentations 'out-ofhours' and 'in-hours' are described. Factors predicting admission were: previous poychiatric admission, symptoms of a psychotic or affective disorder and non-permanent accommodation. The survey has implications for the process of triage in A\&E departments and the organisation of mental health liaison services.
\end{abstract}

The Patient's Charter states that people attending accident and emergency (A\&E) department will "be seen immediately" and have "their need for treatment assessed". This includes the "immediate admission' of people with acute psychiatric illness, which has been identified as one of the core services in the National Health Service. In most districts, the assessment of acutely presenting psychiatric illness takes place in a general hospital A\&E department. However, the management of such cases has been severely affected by the closure of A\&E departments, which has resulted in remaining $A \& E$ departments being overloaded and waiting times lengthening, and the closure of acute psychiatric beds, which has led to demand exceeding supply and bed occupancy rates above 100\% (Hollander \& Slater, 1994).

The aims of this study were to obtain an impression of what happens to people presenting with psychiatric problems to an inner-city $A \& E$ department, and to identify patterns of presentation (e.g. comparing 'in-hours' and 'out-ofhours'). In particular, we were interested in how the management of particular groups (e.g. those who had taken an overdose and those with severe mental illness) concurred with The Health of the Nation goals.

The survey was carried out in an A\&E department in a north London teaching hospital. Every person presenting to $A \& E$ has a casualty incident card completed and is triaged by an
A\&E nurse who assigns a triage code ranging from $\mathrm{Pl}$ to $\mathrm{P4}$. This is a nationally agreed coding designed to reflect the urgency of the presentation ( $\mathrm{P} 1$, life-threatening problem to be seen within 15 minutes; P2, urgent but not lifethreatening problem to be seen within 1 hour; P3, non-urgent case to be seen within 2 hours; and P4, to be seen within 4 hours). People are then seen by an A\&E senior house officer (SHO) who refers patients to appropriate specialities. For psychiatric referrals, a mental health liaison team operates between 9.00 am and $5.00 \mathrm{pm}$, with a duty system operating outside these hours.

\section{The study}

Casualty incident cards were examined for 17000 patients, representing every $A \& E$ attendance over three months. All the casualty incident cards were scrutinised by psychiatrists to ensure that a patient presenting with what appeared to be a non-psychiatric complaint, but later diagnosed as having a psychiatric problem. would not be excluded. A total of 630 data collection forms were completed for people presenting with psychiatric problems. Data collected included socio-demographic details, reason for and mode of referral, triage priority. waiting time, past psychiatric history, diagnosis and disposal details.

Data were analysed using the Statistical Package for the Social Sciences (Windows version, Release 6.0). Chi-squared, odds ratios and confidence intervals were used to examine differences between groups. Forward stepwise logistic regression was used to perform multivariate analysis of dichotomous dependent variables.

\section{Findings}

\section{Socio-demographic factors}

The gender incidence of people presenting with psychiatric problems was approximately equal (male $56 \%$, female $44 \%$ ). Ninety-two per cent of cases were between 17 and 65 years of age. Thirty-nine per cent of cases presented to A\&E 
between $9.00 \mathrm{am}$ and $5.00 \mathrm{pm}$ ('in-hours') and $51 \%$ between $5.00 \mathrm{pm}$ and 9.00 am ('out-ofhours'). Thirty-four per cent of the cases were from outside the immediate catchment area of the hospital.

\section{Triage}

Forty-seven per cent of cases were given a P3 coding. The actual waiting times were only recorded in $38 \%$ of cases and $42 \%$ waited for more than two hours.

\section{Mode of and reason for referral}

Forty-seven per cent of cases had referred themselves to the A\&E department and a further $19 \%$ had been brought to $A \& E$ by a partner or family member. Forty per cent had deliberately harmed themselves, $35 \%$ by taking an overdose of one or more over-the-counter drugs. Thirtythree per cent had features of anxiety or depression and $17 \%$ presented with psychotic symptoms. Eleven per cent were intoxicated through the use of alcohol or drugs. Twenty per cent of cases were referred directly by a triage nurse to the mental health liaison team and $27 \%$ by an A\&E senior house officer. Forty-nine per cent of cases were not referred (this included $13 \%$ who were admitted to the overnight stay ward or under a medical surgical team).

\section{Diagnosis}

The diagnoses recorded in casualty incidence cards are shown in Table 1 . Of the $65 \%$ of cases where a diagnosis was made, half appeared to have a psychotic or affective disorder.

\section{Disposal}

The disposal of cases is shown in Table 2. Thirtyone per cent of cases were admitted, but only $18 \%$ immediately to a psychiatric ward. Twentyseven per cent of cases did not wait to be seen

Table 1. Diagnoses given to people presenting with psychiatric problems

\begin{tabular}{lc}
\hline Diagnoses & $\%$ \\
\hline Depression & 16 \\
Schizophrenia & 13 \\
Alcohol dependence & 12 \\
Personality disorder & 8 \\
Anxiety disorder & 6 \\
Drug dependence & 3 \\
Bipolar affective disorder & 2 \\
Organic brain disorder & 1 \\
No psychiatric disorder & 5 \\
No diagnosis given & 35 \\
\hline
\end{tabular}

by a psychiatrist or an A\&E SHO, despite having been triaged by a nurse. Of those admitted to a psychiatric ward, less than $10 \%$ were detained under a section of the Mental Health Act 1983.

People presenting with deliberate self-harm

Of those cases presenting with an overdose or deliberate self-harm, $84 \%$ had taken an overdose and $71 \%$ presented to $A \& E$ between $5.00 \mathrm{pm}$ and $9.00 \mathrm{am}$. Eighty per cent of these had a triage code of P3 or lower, and only $40 \%$ had their waiting time recorded. Forty per cent of these cases came from outside the hospital's catchment area and $27 \%$ disappeared from the $A \& E$ department before being seen by an A\&E SHO or psychiatrist.

\section{People presenting with psychotic symptoms}

Of those presenting with symptoms suggestive of severe mental illness, such as paranoid delusions or auditory hallucinations, $54 \%$ came to A\&E between $5.00 \mathrm{pm}$ and $9.00 \mathrm{am}$ : $16 \%$ of these had taken an overdose; $80 \%$ had a triage code of P3 or lower; and $63 \%$ had no waiting time recorded. Thirty-three per cent were admitted to a psychiatric ward following assessment, but $19 \%$ left the A\&E department before being seen.

Differences between people presenting 'out-ofhours' and 'in-hours'

People were more likely to have taken an overdose 'out-of-hours' than 'in-hours' $(P=0.005)$. People presenting 'out-of-hours' were also more likely to disappear from $A \& E$ before being assessed than those seen 'in-hours' $(P=0.05)$.

People coming to A\&E 'in-hours' were more likely to be depressed than those seen out-ofhours' $(P=0.03)$. 'In-hours' presentations were also more likely to be referred to a psychiatrist $(P=0.01)$ or be admitted to a psychiatric ward $(P=0.02)$. 'In-hours' presentations were more likely to receive a psychiatric diagnosis that

Table 2. Disposal of people presenting with psychiatric problems

\begin{tabular}{lr}
\hline & $\%$ \\
\hline Psychiatric admission & 18 \\
Home/back to GP & 18 \\
Admitted under other team & 13 \\
Liaison team referral & 11 \\
Out-patient referral & 7 \\
Alcohol/drug services & 2 \\
Social services referral & $<1$ \\
Not stated & 4 \\
Did not wait & 27 \\
\hline
\end{tabular}


was written on the casualty incident card than those seen 'out-of-hours' $(P<0.001)$.

\section{Factors predicting admission}

Factors associated with psychiatric admission were: previous psychiatric admission $(P<0.001)$; symptoms of psychotic or affective disorder $(P<0.001) ;$ no current contact with services $(P<0.001) ; \quad$ non-permanent accommodation $(P=0.007) ;$ single status $(P=0.022) ;$ and Section 136 referral $(P=0.013)$. When these independent variables were analysed using forward stepwise logistic regression, three variables were found to account for the variance in the regression equation: previous psychiatric admission (odds ratio $=4.4,95 \% \mathrm{CI}=3.0-6.9$ ); symptoms of psychotic or affective disorder (odds ratio $=2.4,95 \%$ $\mathrm{CI}=1.3-2.9$ ); and non-permanent accommodation (odds ratio $=2.9,95 \% \mathrm{CI}=1.8-4.5$ ).

The only factor associated with a non-psychiatric admission for a person presenting with psychiatric problems was deliberate self-harm $(P<0.001)$.

\section{Comment}

There is well documented evidence of mounting workloads within A\&E departments, and the British Medical Association has recommended an increase in emergency admission units to tackle increasing $A \& E$ waiting times (British Medical Journal, 1996). Other proposals include increasing the number of nurse practitioners in $A \& E$ departments and the use of telephone triage to direct inappropriate referrals to other services. This supposes that triage is a reliable method for determining access to $A \& E$ assessment and admission. A number of studies have indicated the opposite (Lowe et al, 1994; Brillman et al, 1996), and in some situations nurse triage has been shown to extend waiting times (George et al, 1992; Bindman, 1995; George et al, 1995).

Dale et al (1995) suggested that $40 \%$ of people presenting to an inner-city (south London) A\&E department could be dealt with in a primary healthcare setting. However, the nurse triage used focused on 'true' accidents and emergencies, such as severe pain or an inability to walk, and not the typical presentations seen in people with psychiatric problems, who may be perceived as having less acute medical needs. More stringent guidelines as to which patients qualify to attend A\&E could have a direct effect on access to services for people with psychiatric problems. For them the current triage system is manifestly not working, and people who should be seen are leaving A\&E departments because they are kept waiting too long. If more than $25 \%$ of people who have taken an overdose leave before being assessed, along with $19 \%$ of those with severe mental illness such as schizophrenia, who may also have harmed themselves in some way, something is seriously wrong.

What is the solution? The development of a cohesive, multi-disciplinary mental health liaison team operating within the A\&E department has been recommended by a joint working party of the Royal College of Psychiatrists and the British Association for Accident and Emergency Medicine (Royal College of Psychiatrists, 1996). However, such teams tend to attract increased referral rates from other specialties as well as $A \& E$, with the result that the service is often overloaded (Brown \& Cooper, 1987). The presence of a liaison team in the $A \& E$ department also encourages bypassing of the need to be seen by an A\&E SHO, which may be appropriate in some cases (e.g. when an individual is violent or disturbed) but carries the risk of physical disorders manifesting as psychiatric illness being overlooked.

Another possibility is to streamline the triage of people with psychiatric problems such that those likely to need admission are prioritised. A previous study by Rosenzweig (1992), in a Minnesota emergency department, claimed a "major improvement in patient care" as a consequence of psychiatric triage. This has obvious resource implications, and educational programmes for A\&E medical and nursing staff and clinical guidelines for managing common psychiatric problems in $A \& E$ are likely to be needed as well (Royal College of Psychiatrists, 1996).

What the present survey has demonstrated is that a history of previous psychiatric admissions is the key determinant in deciding the need for admission. Schnyder et al (1995) made a similar observation in an A\&E department in Switzerland, and additionally identified unemployment. living alone and a diagnosis of a psychotic or mood disorder as being associated with the need for admission.

We would suggest that rather than closing A\&E doors to people with psychiatric problems, we should be making assessment more accessible. particularly where people may be having diffculties coping and lack support. To achieve this, mental health liaison teams operating in A\&E departments need to be working in close cooperation with triage nurses and other A\&E staff to ensure that people with psychiatric problems are not simply allowed to vanish into the night. If this does not happen. The Health of the Nation will seem yet another pipe-dream and lives are likely to be lost.

\section{Acknowledgements}

We thank Dr Tim Stevens, Dr Jane Myat and Dr Ian Prenelle for their invaluable help in scrutinising the casualty incident cards. 


\section{References}

BRTISH MEDICAL JoURNAL News (1996) BMA suggests ways to end long waits in casualty departments. British Medical Joumal, 313, 646.

BindMAN. A. B. (1995) Trlage in accident and emergency departments. British Medical Joumal, 311, 404.

BRown, A. \& COOPER, A. F. (1987) The impact of liaison psychiatry service on patterns of referral in a general hospital. British Journal of Psychiatry, 160, 83-87.

Briluman, J. C., Doezema, D., TANDBERG, D., et al (1996) Trlage: limitations in predicting need for emergency care and hospital admission. Annals of Emergency Medicine. 27. 493-500.

DAle, J., GREen. J., REID, F., et al (1995) Primary care in the accident and emergency department. British Medical Journal, 311, 423-426.

George, S., ReAD, S., WILLIAMS, B. (1995) Nurse triage time increases emergency department waiting times. British Medical Journal, $311,1305$.

- . - WestLAKE, L., et al (1992) Evaluation of nurse triage in a British accident and emergency department. British Medical Journal, 304, 876-878.

HOLLANDER, D. \& SLATER, M. S. (1994) 'Sorry, no beds': a problem for acute psychiatric admissions. Psychiatric Bulletin, 18, 534-537.
Lowe, R. A., Bindman, A. B., UlRich, S. K., et al (1994) Refusing care to emergency department patients: evaluation of published triage guidelines. Annals of Emergency Medicine, 23, 286-293.

Rosenzweig, L. (1992) Psychiatric triage: a cost-effective approach to quality management in mental health. Joumal of Psychosocial Nursing and Mental Health Services, so, 5-8.

Royal Colngge Of PSYChIATRISTs (1996) Psychiatric Services to Accident and Emergency Departments (Council Report CR43). London: Royal College of Psychiatrists.

SCHNYDER, U., VALACH, L. \& HEIM, E. (1995) Coping and the decision to hospitalize in emergency psychiatry. General Hospital Psychiatry. 17, 362-370.

*David Ellis, Consultant in General Adult and Liaison Psychiatry, Waterlow Unit, Camden and Islington Community Health Services NHS Trust, Highgate Hill, London N19 5NF and Simon Lewis, Registrar in Psychiatry

*Correspondence 